\title{
Sleep disturbance after pediatric traumatic brain injury: critical knowledge gaps remain for the critically injured
}

This article was published in the following Dove Press journal:

Nature and Science of Sleep

\section{Cydni N Williams' \\ Miranda M Lim ${ }^{2-5}$ \\ Steven A Shea ${ }^{5}$}

'Department of Pediatrics, Division of Pediatric Critical Care, ${ }^{2}$ Department of Neurology, ${ }^{3}$ Department of Medicine, ${ }^{4}$ Department of Behavioral Neurosciences, ${ }^{5}$ Oregon Institute of Occupational Health Sciences, Oregon Health \& Science University, Portland, OR, USA
Correspondence: Steven A Shea Oregon Institute of Occupational Health Sciences, 318I SW Sam Jackson Park Road, Oregon Health \& Science University, Portland, OR 97239, USA Email sheast@ohsu.edu
Traumatic brain injury (TBI), the alteration of brain function or brain pathology following external force, is common in children. TBI affects the sleep of victims, and poor sleep itself can impair recovery from TBI. Due to the developing brains of children, it is especially important to understand the complex interactions between sleep and TBI. Such understanding could lead toward optimizing recovery from TBI in children. Thus, here, we introduce the main issues in this field with a specific focus on the pediatric population and point out the important gaps in knowledge that need to be filled.

TBI accounts for 60,000 pediatric hospitalizations in the USA annually. ${ }^{1}$ Half of these children require critical care admission for serious injuries such as skull fractures and intracranial hemorrhage (critical TBI). ${ }^{2}$ Injury and critical care hospitalization leave survivors with physical, cognitive, and psychosocial morbidities encompassed by the postintensive care syndrome. ${ }^{3}$ Few studies have assessed these important morbidities in survivors of pediatric critical TBI, and interventions to improve outcomes are limited. Sleep wake disturbances (SWD) are increasingly recognized as an important morbidity following TBI and as a barrier to recovery in adult TBI and in concussion (the mildest form of TBI without identified intracranial pathology). SWD in pediatric survivors of critical TBI have been under-appreciated by clinicians and under-evaluated by researchers but may be key to improving the important myriad of sequelae suffered by these children.

Sleep is integral to many physiologic systems, and in children, it is critical for brain maturation and development. ${ }^{4,5}$ SWD during childhood brain development, through effects on synaptic plasticity and memory consolidation, may be particularly impactful on long-term pediatric health. ${ }^{6,7} \mathrm{SWD}$ in otherwise healthy children are associated with physical, cognitive, and psychosocial impairments and may substantially compound the negative health consequences of pediatric diseases. ${ }^{8-10}$ SWD of any type are reported in over half of all TBI survivors, occur across all spectrums of severity and location of TBI, and persist for years after injury. ${ }^{711}$ SWD including insomnia, awakenings, daytime fatigue, and sleep disordered breathing are reported in adult TBI survivors though to date are poorly quantified in children. ${ }^{12,13}$ SWD after TBI are associated with impaired functional outcomes, decreased participation in activities, and reduced quality of life. ${ }^{14,15}$ Data from our Pediatric Neurocritical Care follow-up clinic show multiple types of SWD complicate recovery in more than half of survivors of pediatric 
critical TBI months after hospital discharge. ${ }^{16}$ However, most pediatric critical TBI survivors do not receive this type of specialized follow-up that includes systematic evaluation of sleep or postintensive care syndrome. Currently, clinicians have little data guiding methods to identify SWD or to support therapeutic interventions for SWD following pediatric critical TBI.

While there has been a recent upswing in pediatric sleep literature, variable methodology is used in these studies and few focus on TBI. ${ }^{17}$ Polysomnography is the gold standard for the diagnosis of some SWD but is not always feasible in clinical and research populations and may fail to diagnose disorders such as insomnia and excessive daytime sleepiness. ${ }^{18} \mathrm{~A}$ recent review of available pediatric sleep questionnaires resulted in 183 tools reported, but only two fulfilled all appropriate psychometric criteria and only 11 fulfilled most criteria. ${ }^{19}$ Actigraphy is increasingly utilized in children for sleep research providing objective data that have been validated against polysomnography for some SWD and also lacks standard methodology or accepted normative data for many measures in children. ${ }^{20}$ It is likely that the combination of well-validated questionnaires and actigraphy is needed to evaluate the multidimensional aspects of SWD in pediatric critical TBI.

SWD literature is dominated by concussion patients in pediatric TBI cohorts, and available reports are often secondary evaluations of data not designed to collect sleep outcomes..$^{13}$ A systematic review in 2015 of SWD after pediatric TBI identified only eight studies exclusive of case reports that included children with critical TBI. ${ }^{13}$ Only one study of 15 patients with critical TBI included objective actigraphy data evaluating sleep, ${ }^{21}$ and only three studies used a validated sleep questionnaire. ${ }^{8,21,22}$ A 2017 study evaluating fatigue after pediatric critical TBI showed that it remained a significant problem 12 months after injury but was not evaluated in conjunction with sleep measures. ${ }^{23}$ Most prior reports do not delineate the specific type of SWD or the severity of SWD in the analysis. Additionally, prior reports stratifying injury severity by Glasgow Coma Scale did not find a significant association with SWD. ${ }^{13,24}$ Glasgow Coma Scale fails to incorporate other concurrent injuries, such as extremity fractures and abdominal trauma, that occur in the majority of pediatric critical TBI patients and have implications for sleep outcomes such as pain, medications, and casting.

The pathophysiology of SWD after critical TBI is unclear but has been attributed to structural and functional disruptions of sleep circuitry, circadian rhythm disturbances, hormonal dysfunction, and comorbidities such as pain and psychological disorders. ${ }^{7}$ However, evaluation of disease mechanisms remains in its infancy, despite a rapidly growing body of literature. ${ }^{7}$ A variety of neural networks, neurotransmitters, and neuropeptides are linked to normal and disordered sleep. After a critical TBI, many of these sleep-related systems are affected either through the primary injury or through the secondary injury related to inflammation and physiologic derangements.

Secondary injury related to inflammation has been underevaluated in TBI with regard to sleep outcomes. TBI induces an acute systemic inflammatory response that increases neuroinflammation and directly injures the brain. ${ }^{25-28}$ Interleukins (ILs) and other proinflammatory cytokines, including IL-1 $\beta$, IL-6, and tumor necrosis factor alpha (TNF $\alpha$ ), are elevated in serum and cerebrospinal fluid after TBI, cross the bloodbrain barrier freely after injury, and are evaluated as mediators of other TBI outcomes. ${ }^{25-28}$ Levels correlate with injury severity, increased intracranial pressure, increased mortality, and worsened Glasgow Outcome Score in TBI survivors. ${ }^{28}$ Chronic elevations of TNF $\alpha$, IL-6, and IL-1 $\beta$ levels weeks to months after TBI correlate with significantly worse Disability Ranking Scale, Glasgow Outcome Score, and slowed trajectory of cognitive recovery. ${ }^{29-31}$ The same inflammatory cytokines elevated after TBI influence sleep through damaging neurons in the hypothalamus, modifying astrocyte and microglial function, altering levels of melatonin and orexin, and impairing circadian regulation. ${ }^{32-36}$ SWD also potentiate chronic inflammation, and this is a proposed mechanism leading to many of the negative health consequences linked to SWD. ${ }^{33,34}$ Despite overlap between inflammation after critical TBI and inflammation in SWD reported separately in the literature, prior studies have not assessed the link between inflammation and SWD following critical TBI.

In sum, SWD after pediatric critical TBI are an important morbidity. There remain substantial gaps in available knowledge due to limited data. Research is needed to identify the incidence, risk factors, and pathophysiologic mechanisms underlying SWD. Untreated SWD delay recovery and compound other morbidities encompassed by postintensive care syndrome, including physical, neurocognitive, and psychosocial dysfunction after pediatric critical TBI (Figure 1). Understanding the burden of SWD in critical TBI survivors is the first step toward identifying effective interventions for SWD and evaluating sleep as a modifiable target for other important morbidities plaguing pediatric survivors of critical TBI. 


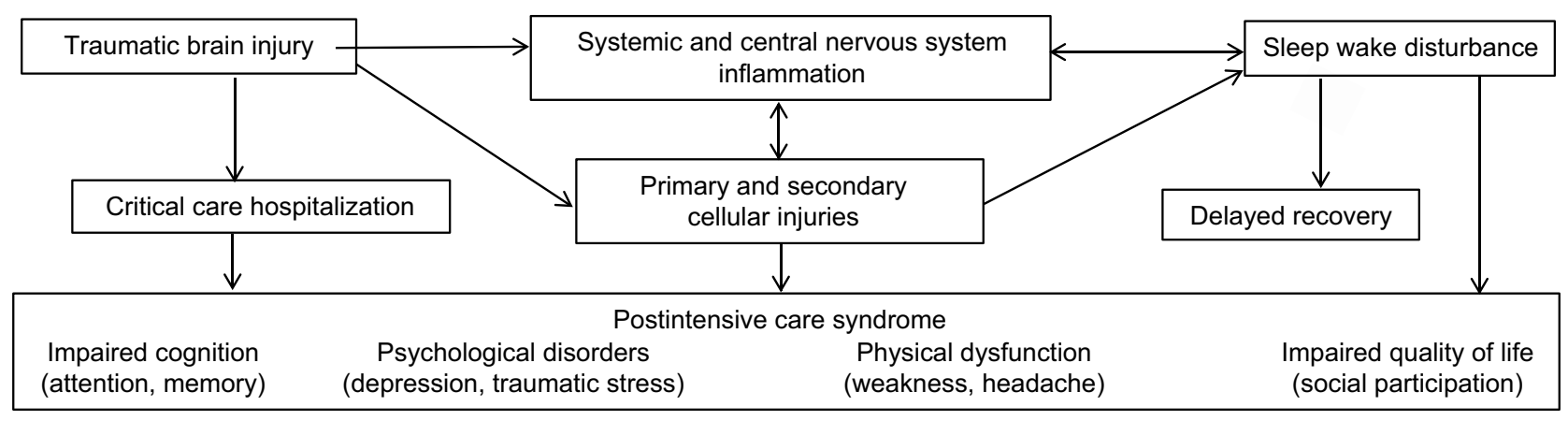

Figure I Proposed relationship between traumatic brain injury, inflammation, sleep wake disorders, and postintensive care syndrome.

\section{Disclosure}

The authors report no conflicts of interest in this work.

\section{References}

1. Faul MXL, Wald MM, Coronado VG [webpage on the Internet]. Traumatic Brain Injury in the United States: Emergency Department Visits, Hospitalizations and Deaths 2002-2006. Atlanta (GA): Centers for Disease Control and Prevention, National Center for Injury Prevention and Control; 2010. Available from: https://www.cdc.gov/traumaticbraininjury. Accessed May 10, 2017.

2. Asemota AO, George BP, Bowman SM, Haider AH, Schneider EB. Causes and trends in traumatic brain injury for United States adolescents. J Neurotrauma. 2013;30(2):67-75.

3. Herrup EA, Wieczorek B, Kudchadkar SR. Characteristics of postintensive care syndrome in survivors of pediatric critical illness: a systematic review. World J Crit Care Med. 2017;6(2):124-134.

4. Volk C, Huber R. Sleep to grow smart? Arch Ital Biol. 2015;153(2-3):99-109.

5. Ringli M, Huber R. Developmental aspects of sleep slow waves: linking sleep, brain maturation and behavior. Prog Brain Res. 2011;193:63-82.

6. Tononi G, Cirelli C. Sleep and the price of plasticity: from synaptic and cellular homeostasis to memory consolidation and integration. Neuron. 2014;81(1):12-34.

7. Sandsmark DK, Elliott JE, Lim MM. Sleep-wake disturbances after traumatic brain injury: synthesis of human and animal studies. Sleep. 2017;40(5).

8. Shay N, Yeates KO, Walz NC, et al. Sleep problems and their relationship to cognitive and behavioral outcomes in young children with traumatic brain injury. J Neurotrauma. 2014;31(14):1305-1312.

9. Owens JA. Neurocognitive and behavioral impact of sleep disordered breathing in children. Pediatr Pulmonol. 2009;44(5):417-422.

10. Gozal D, Kheirandish-Gozal L. Neurocognitive and behavioral morbidity in children with sleep disorders. Curr Opin Pulm Med. 2007;13(6):505-509.

11. Beebe DW, Krivitzky L, Wells CT, Wade SL, Taylor HG, Yeates KO. Brief report: parental report of sleep behaviors following moderate or severe pediatric traumatic brain injury. $J$ Pediatr Psychol. 2007;32(7):845-850.

12. Singh K, Morse AM, Tkachenko N, Kothare SV. Sleep disorders associated with traumatic brain injury-a review. Pediatr Neurol. 2016;60:30-36.

13. Gagner C, Landry-Roy C, Laine F, Beauchamp MH. Sleep-wake disturbances and fatigue after pediatric traumatic brain injury: a systematic review of the literature. J Neurotrauma. 2015;32(20):1539-1552.

14. Aaro Jonsson CC, Emanuelson IM, Charlotte Smedler A. Variability in quality of life 13 years after traumatic brain injury in childhood. Int J Rehabil Res. 2014;37(4):317-322.
15. Tham SW, Palermo TM, Vavilala MS, et al. The longitudinal course, risk factors, and impact of sleep disturbances in children with traumatic brain injury. J Neurotrauma. 2012;29(1):154-161.

16. Williams CN, Kirby A, Piantino J. If you build it, they will come: initial experience with a multi-disciplinary pediatric neurocritical care followup clinic. Children (Basel). 2017;4(9):83.

17. Lam DJ, Shea SA. A growth spurt in pediatric sleep research. Nat Sci Sleep. 2016;8:133-135.

18. Mouthon AL, Huber R. Methods in pediatric sleep research and sleep medicine. Neuropediatrics. 2015;46(3):159-170.

19. Spruyt K, Gozal D. Pediatric sleep questionnaires as diagnostic or epidemiological tools: a review of currently available instruments. Sleep Med Rev. 2011;15(1):19-32.

20. Meltzer LJ, Montgomery-Downs HE, Insana SP, Walsh CM. Use of actigraphy for assessment in pediatric sleep research. Sleep Med Rev. 2012;16(5):463-475.

21. Sumpter RE, Dorris L, Kelly T, McMillan TM. Pediatric sleep difficulties after moderate-severe traumatic brain injury. J Int Neuropsychol Soc. 2013;19(7):829-834.

22. Osorio MB, Kurowski BG, Beebe D, et al. Association of daytime somnolence with executive functioning in the first 6 months after adolescent traumatic brain injury. PM R. 2013;5(7):554-562.

23. Crichton A, Anderson V, Oakley E, et al; Biomarker and Quality of Life in Children with Traumatic Brain Injury Group. Fatigue following traumatic brain injury in children and adolescents: a longitudinal follow-up 6 to 12 months after injury. J Head Trauma Rehabil. 2017;33(3):200-209.

24. Baumann CR, Werth E, Stocker R, Ludwig S, Bassetti CL. Sleep-wake disturbances 6 months after traumatic brain injury: a prospective study. Brain. 2007;130(pt 7):1873-1883.

25. Kelley BJ, Lifshitz J, Povlishock JT. Neuroinflammatory responses after experimental diffuse traumatic brain injury. J Neuropathol Exp Neurol. 2007;66(11):989-1001.

26. Das M, Mohapatra S, Mohapatra SS. New perspectives on central and peripheral immune responses to acute traumatic brain injury. J Neuroinflammation. 2012;9:236.

27. Hinson HE, Rowell S, Morris C, Lin AL, Schreiber MA. Early fever after trauma: does it matter? J Trauma Acute Care Surg. 2018;84(1):19-24.

28. Hinson HE, Rowell S, Schreiber M. Clinical evidence of inflammation driving secondary brain injury: a systematic review. J Trauma Acute Care Surg. 2015;78(1):184-191.

29. Licastro F, Hrelia S, Porcellini E, et al. Peripheral inflammatory markers and antioxidant response during the post-acute and chronic phase after severe traumatic brain injury. Front Neurol. 2016;7:189.

30. Kumar RG, Diamond ML, Boles JA, et al. Acute CSF interleukin-6 trajectories after TBI: associations with neuroinflammation, polytrauma, and outcome. Brain Behav Immun. 2015;45:253-262. 
31. Kumar RG, Boles JA, Wagner AK. Chronic inflammation after severe traumatic brain injury: characterization and associations with outcome at 6 and 12 months postinjury. J Head Trauma Rehabil. 2015;30(6):369-381.

32. Clark IA, Vissel B. Inflammation-sleep interface in brain disease: TNF, insulin, orexin. J Neuroinflammation. 2014;11:51.

33. Kapsimalis F, Basta M, Varouchakis G, Gourgoulianis K, Vgontzas A, Kryger M. Cytokines and pathological sleep. Sleep Med. 2008;9(6): 603-614.
34. Weschenfelder J, Sander C, Kluge M, Kirkby KC, Himmerich H. The influence of cytokines on wakefulness regulation: clinical relevance, mechanisms and methodological problems. Psychiatr Danub. 2012;24(2):112-126.

35. Opp MR. Cytokines and sleep. Sleep Med Rev. 2005;9(5):355-364.

36. Kapsimalis F, Richardson G, Opp MR, Kryger M. Cytokines and normal sleep. Curr Opin Pulm Med. 2005;11(6):481-484.

Dove Medical Press encourages responsible, free and frank academic debate. The content of the Nature and Science of Sleep 'Editorial' section does not necessarily represent the views of Dove Medical Press, its officers, agents, employees, related entities or the Nature and Science of Sleep editors. While all reasonable steps have been taken to confirm the content of each Editorial, Dove Medical Press accepts no liability in respect of the content of any Editorial, nor is it responsible for the content and accuracy of any Editorial.

\section{Publish your work in this journal}

Nature and Science of Sleep is an international, peer-reviewed, open access journal covering all aspects of sleep science and sleep medicine, including the neurophysiology and functions of sleep, the genetics of sleep, sleep and society, biological rhythms, dreaming, sleep disorders and therapy, and strategies to optimize healthy sleep. The manuscript
Dovepress

management system is completely online and includes a very quick and fair peer-review system, which is all easy to use. Visit http://www. dovepress.com/testimonials.php to read real quotes from published authors. 